\title{
Characterizing a Lytic Bacteriophage Infecting Methicillin-Resistant Staphylococcus aureus (MRSA) Isolated From Burn Patients
}

\author{
Masoume Hallajzadeh ${ }^{1,2}$, Ali Mojtahedi ${ }^{3}$, Nour Amirmozafari ${ }^{1,2,{ }^{*}}$ and Vahid Pirhajati Mahabadi ${ }^{4,5}$ \\ ${ }^{1}$ Department of Microbiology, School of Medicine, Iran University of Medical Sciences, Tehran, Iran \\ ${ }^{2}$ Microbial Biotechnology Research Center, Iran University of Medical Sciences, Tehran, Iran \\ ${ }^{3}$ Department of Microbiology, Department of Parasitology and Immunology, Guilan University of Medical Sciences, Rasht, Iran \\ ${ }^{4}$ Neuroscience Research Center, Iran University of Medical Sciences, Tehran, Iran \\ ${ }^{5}$ Cellular and Molecular Research Center, Iran University of Medical Sciences, Tehran, Iran \\ "Corresponding author: Department of Microbiology, Microbial Biotechnology Research Center, School of Medicine, Iran University of Medical Sciences, Tehran, Iran. Email: \\ amirmozafari@iums.ac.ir
}

Received 2019 March 16; Revised 2020 January 02; Accepted 2020 January 05.

\begin{abstract}
Background: Methicillin-resistant Staphylococcus aureus (MRSA) is a significant threat to human health. It is a multidrug-resistant (MDR) pathogen capable of causing a variety of diseases. Also, MRSA is one of the most important nosocomial pathogens in burn infection. As a treatment strategy against MRSA infections, phage therapy has the potential of becoming an alternative remedy.

Objectives: The present study aimed to isolate and characterize a lytic bacteriophage from hospital sewage to be effective against burn wound-infecting MRSA isolates.

Methods: Staphylococcus aureus strains were isolated from hospitalized burn patients. The strains were confirmed as MRSA by the Kirby-Bauer disk diffusion method using penicillin, methicillin, and oxacillin, as well as the PCR assay for the mecA gene. The phage was isolated from the hospital sewage and tittered by the double layer agar (DLA) method. The spot test was used for host range determination. The latent period and burst size were estimated from a one-step growth curve. The phage morphology was observed by electron microscopy. The nature of the nucleic acid of the isolated bacteriophages was confirmed by Rnase A, Dnase I, and six restriction enzymes.

Results: The titer, latent period, and burst size of the isolated phage were determined to be $1 \times 10^{9} \mathrm{PFU} / \mathrm{mL}, 20 \mathrm{~min}$, and $190 \mathrm{PFU}$ per infected cell, respectively. It displayed a broad host range for MRSA bacteria by the spot test (27 out of 30 isolates). Electron microscopy observation demonstrated that the phage belonged to the Myoviridea family. Digestion profiles of Rnase A, Dnase I, and six restriction enzymes in $1 \%$ agarose gel electrophoresis showed that the genome of the isolated phage was a double-stranded DNA with a size of $<\sim 23 \mathrm{kbp}$.

Conclusions: The isolated phage (MH-1) was active against a wide range of MRSA strains recovered from burn patients. Its specificity and remarkable lytic effects on MRSA strains emphasized that it could be a suitable candidate for use in prophylaxis and treatment of these clinical infections.
\end{abstract}

Keywords: Staphylococcus aureus, MRSA, MDR, Burn Patients, Bacteriophage, Wastewater

\section{Background}

The increasing appearance of multidrug-resistant (MDR) microorganisms in clinics is a severe rising threat to human health (1). Most recently, an estimated 2.5 million people acquire antibiotic-resistant infections every year in Europe and the USA leading to approximately 50,000 deaths (2). Methicillin-resistant Staphylococcus aureus (MRSA) is an MDR organism. It was initially detected during the early 1960s in the United Kingdom and is now regarded as a major hospital-acquired pathogen throughout the world $(3,4)$. Methicillin-resistant $S$. aureus is one of the most common nosocomial pathogens infecting burn wounds (5). Burn patients are at an increased risk of colonization and subsequent infections by nosocomial pathogens due to the disruption of the skin protective barrier and reduction of immune responses, which can lead to poor clinical outcomes and increased morbidity and mortality rates (6). There exist reports of the outbreaks of MRSA and evidence of increasing MRSA strains in burn units. In addition, reports indicate that burn units and ICUs may act as reservoirs for MRSA. Despite the full compliance with infection control programs, the acquisition and transmission of MRSA are continuous problems in burn units (7). 
Staphylococcus aureus is a common commensal bacterium that, as an opportunistic pathogen, is capable of causing a variety of diseases ranging from mild skin infections and food poisoning to fatal infections like endocarditis, pneumonia, osteomyelitis, and toxic shock syndrome. It is also a leading cause of infections associated with catheters and devices (8-11). The pathogenesis of $S$. aureus strains are related to the expression of different virulence factors, including cell surface components (e.g., collagen-binding protein, clumping factor, fibronectinbinding protein, and elastin binding protein) and secreted factors (e.g., staphylokinase, toxic shock syndrome toxin-1, hemolysin, panton-valentine leukocidin (PVL), exfoliative toxins (eta and etb), staphylococcal enterotoxins (SEs), and lipase) (12).

Unfortunately, MRSA is resistant to all beta-lactam antimicrobial drugs such as penicillin, cefoxitin, and oxacillin, except for newer cephalosporins with anti-MRSA activity. The MRSA isolates are susceptible only to glycopeptides, such as vancomycin (13). In addition to the increasing prevalence of MRSA, the emergence of vancomycin-resistant or vancomycin-intermediate $S$. aureus (VRSA or VISA) has caused a serious problem $(3,14)$. Also, community-acquired MRSA infections have increasingly been identified in the past two decades (10). This microorganism has been declared as an international concern by the World Health Organization $(1,15,16)$. It is estimated that $70 \%$ of mortality in burn units is related to infections. Thus, the management of burn patients is a significant problem because of the outbreaks of infections in burn units and the presence of many MDR strains. Additionally, hospital burn units are the main reservoirs for MRSA with the potential for rapid dissemination in the hospital environment (17). Shahsavan et al. (5) isolated S. aureus strains from burn patients in Tehran and reported that most MRSA isolates were MDR and showed resistance to $\beta$-lactams, macrolides, tetracyclines, and aminoglycosides. As a result, therapeutic strategies to encounter clinical infections caused by these bacteria have become limited (2). Therefore, alternative antibacterial agents and programs must be developed (2). Moreover, due to the rapid acquisition of resistance to new antibiotics and rising production costs, there has been little incentive to develop new antibacterial agents $(2,14,18)$.

Phage therapy has attracted a great deal of attention as a strategy against MRSA infections and to provide a new solution against the threat of MDR infections (19). This approach uses bacterial viruses (phages) that can specifically attack pathogenic bacteria and kill them (20). Phage therapy has the potential of being highly specific merely against a species or even a strain responsible for infection $(8,21,22)$. Moreover, their remarkable specificity pre- vents them from affecting human cells and the composition of the body microbiota and inducing antimicrobial resistance in different bacterial species $(1,22)$.

\section{Objectives}

The aim of the present study was to isolate and characterize a lytic bacteriophage from hospital sewage to be effective against burn wound-infecting MRSA isolates.

\section{Methods}

\subsection{Isolation and Characterization of Bacterial Strains}

During a nine-month period starting from September 2017 to May 2018, 30 MRSA isolates were obtained from burn patients hospitalized at Motahari Hospital in Tehran, Iran, and transferred to the Research Laboratory of Microbiology Department, Iran University of Medical Sciences. Strains were identified as S. aureus by Gram staining, coagulase, catalase, oxidase, and DNase production, as well as mannitol fermentation and PCR amplification of the protein A gene (spa). The Kirby-Bauer disk diffusion method was performed to confirm their resistance to penicillin, methicillin, and oxacillin, as recommended by the Clinical and Laboratory Standards Institute (CLSI) guidelines. Additionally, PCR assays were carried out for the mecA gene. After the identification of MRSA isolates, they were stored in $20 \%$ glycerol at $-20^{\circ} \mathrm{C}$. Three clinical isolates $(\mathrm{MH}-1, \mathrm{~S} 1$, and M2) plus a reference strain of MRSA (ATCC 43300) were used as hosts for bacteriophage isolation and propagation from wastewater samples.

\subsection{Wastewater Sample Collection for Bacteriophage Isolation}

Several wastewater samples were taken from untreated sewage ponds of Motahari Hospital and screened as sources of bacteriophages. The samples were centrifuged at 2,500 $\times \mathrm{g}$ for $20 \mathrm{~min}$ to separate bacterial cells and debris. The supernatant was filtered through $0.45 \mu \mathrm{m}$ filters, transferred to a clean tube, and stored at $4^{\circ} \mathrm{C}$ (23).

\subsection{Isolation and Purification of Bacteriophages}

For phage isolation, $10 \mathrm{~mL}$ of exponential phase culture of clinical and standard strains of $S$. aureus was mixed with $10 \mathrm{~mL}$ of fresh LB broth (2X) and $10 \mathrm{~mL}$ of filtered sewage sample, and incubated overnight at $37^{\circ} \mathrm{C}$ with shaking at $80 \mathrm{rpm}$. The culture was then centrifuged for 20 min at $2,500 \times \mathrm{g}$ to remove bacteria and the supernatant was filtered through $0.22 \mu \mathrm{m}$ pore size Millipore filters (for phage amplification, the simultaneous culturing step was repeated three or more times). This lysate (supernatant) was examined for lytic phage in the plaque assay by the Double-layer Agar (DLA) method (23). 


\subsection{Double Layer Agar}

In this method, one milliliter of phage lysate was mixed with $500 \mu \mathrm{L}$ of a stationary phase culture of host S. aureus. After $10 \mathrm{~min}$ incubation at $37^{\circ} \mathrm{C}, 5 \mathrm{~mL}$ of LB top $\operatorname{agar}\left(4 \mathrm{mM} \mathrm{CaCl}_{2}, 4 \mathrm{mM} \mathrm{MgSO}_{4}, 0.7 \%(\mathrm{w} / \mathrm{v})\right.$ agar, at $\left.45^{\circ} \mathrm{C}\right)$ was added, mixed, and overlaid onto fresh LB agar plates $(1.5 \%(w / v)$ agar) prepared before. After solidifying, the plates were incubated overnight at $37^{\circ} \mathrm{C}$ until lysis zones appeared (24).

\subsection{Purification of Bacteriophage}

Single plaques from each plate were picked by a sterile Pasteur pipette and placed in a tube containing one milliliter of LB broth $\left(45^{\circ} \mathrm{C}\right)$. One milliliter of stationary phase culture of host bacteria was added to each tube and incubated for $24 \mathrm{~h}$ at $37^{\circ} \mathrm{C}$ and $80 \mathrm{rpm}$. On the next day, the lysate was screened for the presence of plaques as described above. Purification was carried out by three serial single-plaque isolations (25).

\subsection{Determination of Bacteriophage Titer}

Ten sterile tubes containing $900 \mu \mathrm{L}$ Luria Bertani (LB) broth were numbered from $10^{-1}$ to $10^{-10}$. Next, $100 \mu \mathrm{L}$ of phage lysate was added to the first tube $\left(10^{-1}\right)$, mixed well, and then $100 \mu \mathrm{L}$ was transferred to the second tube $\left(10^{-2}\right)$ in series $\left(10^{-1}\right.$ to $\left.10^{-10}\right)$. The same pattern was used to make serial dilutions. Then, $100 \mu \mathrm{L}$ of an exponential phase culture of host MRSA was added to each tube and mixed with $100 \mu \mathrm{L}$ of each dilution of phage lysate $\left(10^{-5}\right.$ to $\left.10^{-9}\right)$. Tubes were incubated for $10 \mathrm{~min}$ at $37^{\circ} \mathrm{C}$ for phage adsorption. Five tubes containing $3 \mathrm{~mL}$ of LB soft agar (0.4\% agar, 4 to $10 \mathrm{mM} \mathrm{CaCl}_{2}$, and $\mathrm{MgSO}_{4}$ ) at $45^{\circ} \mathrm{C}$ were numbered from $10^{-5}$ to $10^{-9}$. The phage and bacterial suspensions were added to soft agar tubes and after mixing were overlaid onto plates containing LB agar (1.5\% agar). Plates were incubated overnight at $37^{\circ} \mathrm{C}$ and the resulting plaques were counted. In this way, PFU/mL was equal to the number of plaques/dilution $\times$ volume of diluted phage added to each plate (26).

\subsection{Host Range Determination}

Thirty MRSA clinical isolates, recovered from burn patients, were used to determine the host range of the isolated bacteriophage. To determine the susceptibility of methicillin-susceptible $S$. aureus (MSSA) strains to phagemediated lysis, 30 of its strains from burn patients were also examined. Bacterial strain susceptibilities were detected by the spot test method described by Kutter with some modifications (24). Briefly, bacterial strains were incubated for $4 \mathrm{~h}$ in LB broth at $37^{\circ} \mathrm{C}$ and $180 \mathrm{rpm}$ (OD 600 $\mathrm{nm}=0.4-0.6)$. Then, $500 \mu \mathrm{L}$ of each bacterial culture was added to $6 \mathrm{~mL}$ of $0.4 \% \mathrm{LB}$ soft agar $\left(45^{\circ} \mathrm{C}\right)$ and poured onto LB agar plates. The plates were left to dry for $10 \mathrm{~min}$. Subsequently, $10 \mu \mathrm{L}$ of the phage lysate $\left(10^{9} \mathrm{PFU} / \mathrm{mL}\right)$ was spotted on lawns of different bacterial strains and incubated overnight at $37^{\circ} \mathrm{C}$ for the formation of a lysis zone. Lytic activity of the isolated phage was also examined on Staphylococcus epidermidis, Enterococcus faecalis, and Enterococcus faecium strains.

\subsection{Electron Microscopy}

In this method, $10 \mu \mathrm{L}$ of polyethylene glycol precipitated phage particles were spotted onto a carbon-coated copper acid grid for 3 - $5 \mathrm{~min}$ and then blotted with a filter paper and stained with $1 \%(\mathrm{w} / \mathrm{v})$ uranyl acetate $(\mathrm{pH}=7)$. It was examined by a Zeiss LEO 906 transmission electron microscope (Carl Zeiss LEO EM 906 E, Germany) at an accelerating voltage of $100 \mathrm{kV}(26)$.

\subsection{Naming the Isolated Bacteriophage}

We named one of our isolated phages as vB-StuM-MH1 according to the newly proposed naming system vBStuP/M/S MHno, where vB refers to bacterial virus, Stu is an abbreviation for genus/species of the host, P refers to podovirus, $M$ to myovirus, $S$ to siphovirus, and MHno to the name and number of the phage. The last part of the name (MH-1) is the phage's common name (27).

\subsection{One-Step Growth Curve}

One-step growth experiments were performed using a method described by Wang et al. (28) with some modifications. Briefly, a mid-exponential-phase culture $(30 \mathrm{~mL})$ of S. aureus $\left(\mathrm{OD}_{600 \mathrm{~nm}}=0.4\right.$ to 0.5$)$ was harvested by centrifugation and re-suspended in $7.5 \mathrm{~mL}$ of fresh LB broth. Phage lysates (109 PFU/mL) were added at an MOI of 0.0005 and incubated at $37^{\circ} \mathrm{C}$ for $15 \mathrm{~min}$ for phage adsorption. The mixture was then centrifuged at $10,000 \times \mathrm{g}$ for $10 \mathrm{~min}$ to remove free phage particles. The pellet was re-suspended in $10 \mathrm{~mL}$ of LB broth and incubated at $37^{\circ} \mathrm{C}$. Samples were removed at 10-min intervals for $2 \mathrm{~h}$. The samples were immediately diluted 10 -fold and plated for phage titration using the DLA method. On the next day, plaques were counted and PFU/mL was calculated as mentioned above.

\subsection{Isolation of Bacteriophage Genome}

The extraction of phage genomic DNA was done according to the Martha and Clokie method with slight modification (26). Briefly, $10 \mathrm{~mL}$ of phage lysates (with $10 \%$ PEG 8000 , and $1 \mathrm{M}$ concentration of $\mathrm{NaCl}$ ) were incubated overnight at $4^{\circ} \mathrm{C}$ and centrifuged at $10,000 \times \mathrm{g}$ for $15 \mathrm{~min}$. The pellets were re-suspended in $500 \mathrm{ml}$ of SM buffer and transferred to a 2-mL Eppendorf tube. A mixture of $5 \mu \mathrm{L}$ of 1 
$\mathrm{mg} / \mathrm{ml}$ DNase I and $2 \mu \mathrm{L}$ of $12.5 \mathrm{mg} / \mathrm{mL}$ RNase A were added to the tube and incubated for $30 \mathrm{~min}$ at $37^{\circ} \mathrm{C}$. Afterward, $12 \mu \mathrm{L}$ of $20 \%$ SDS and $5 \mu \mathrm{L}$ of $10 \mathrm{mg} / \mathrm{mL}$ proteinase $\mathrm{K}$ were added to the mixture and incubated for $30 \mathrm{~min}$ at $37^{\circ} \mathrm{C}$. Extraction was carried out with $0.5 \mathrm{~mL}$ of phenol: chloroform: isoamyl alcohol (25:24:1) solution. The mixture was spun for $5 \mathrm{~min}$ at $15,000 \times \mathrm{g}$ for phase separation. The supernatant was transferred into a fresh tube and extracted once with $0.5 \mathrm{ml}$ of chloroform: isoamyl alcohol (24:1) solution, followed by centrifugation for $5 \mathrm{~min}$ at $8,000 \times \mathrm{g}$. The supernatant was transferred into a fresh 2-mL Eppendorf tube and $500 \mu \mathrm{L}$ of $100 \%$ isopropanol and $45 \mu \mathrm{L}$ of $3 \mathrm{M}$ sodium acetate $(\mathrm{pH}=5.2)$ were added. The DNA was left for $30 \mathrm{~min}$ to precipitate at room temperature. Following centrifugation for $20 \mathrm{~min}$ at $14,000 \times \mathrm{g}$, the DNA pellet was washed twice with $70 \%$ ethanol and left to dry. The dried DNA pellet was re-suspended in $50 \mu \mathrm{L}$ of distilled water. The phage genomic DNA concentration and quality were determined using a NanoDrop spectrophotometer (Nanodrop One C, Thermo Fisher Scientific, assembled in USA), following the instructions provided by the manufacturer. Then, $10 \mu \mathrm{L}$ of genomic DNA was resolved by electrophoresis on the $0.1 \%$ agarose gel with DNA molecular weight marker ( $\lambda$-Hind III digest) and D2000 DNA size marker (Takara).

\subsection{Restriction Digestion of Phage DNA}

The DNA of the isolated bacteriophage was digested for 5 - 16 h using Rnase A, Dnase I, and six restriction endonucleases (EcoRV, EcoRI, HaeIII, XbaI, SmaI, SacII, and EcoRV) purchased from Thermo scientific (EU), Lithuania. After the enzymatic digestion, restriction fragments were separated by electrophoresis on a $1 \%$ agarose gel containing safe stain (SMO Bio-FluoroVue Nucleic Acid Gel Stain (prestain)) in TBE buffer (Tris-boric acid-EDTA), at $90 \mathrm{~V}$ in a peQ Lab agarose gel electrophoresis system (peQLAB, E0303, Taiwan). Gene ruler $10 \mathrm{~Kb}$ DNA ladder (Thermo Fisher scientific) was used as a size marker. The gel was visualized in a gel documentation system (Vilber Lourmat, E-Box CX5.TS, France). Restriction digestions were performed in triplicate.

\subsection{Bacteriophage Storage}

Phage lysate was filtered and precipitated by adding polyethylene glycol 8,000 (BIO BASIC Canada INC. Cat. \#: PB0433) and $\mathrm{NaCl}$ (Merck, EMSURE® ACS, ISO, Reag. Ph Eur, Germany) to final concentrations of $10 \%$ and $1 \mathrm{M}$, respectively, followed by incubation at $4^{\circ} \mathrm{C}$ for $18 \mathrm{~h}$. The lysate was centrifuged at $10,000 \times \mathrm{g}$ for $20 \mathrm{~min}$. The phage pellet was re-suspended in SM buffer $\left(100 \mathrm{mM} \mathrm{NaCl}, 10 \mathrm{mM} \mathrm{MgSO}_{4}, 10\right.$ mM Tris- $\mathrm{HCl}[\mathrm{pH}=7.5])$ with $50 \%(\mathrm{v} / \mathrm{v})$ glycerol and stored at $80^{\circ} \mathrm{C}$ for long-term use. For short-term use, prepared stocks were stored at $4^{\circ} \mathrm{C}$.

\section{Results}

\subsection{Bacteriophage Isolation}

A total of six phages were isolated. Phage MH-1 was chosen for host range determination and continuing the study.

\subsection{Host Range Analysis}

Of the 30 MRSA and 30 MSSA isolates, 27 strains (90\%) and 26 strains (86.6\%) were sensitive to the isolated phage, respectively, and formed the zone of lysis in the spot test (Figure 1). The lytic activity of the isolated phage was also examined on three other bacterial species. All of the S. epidermidis, E. faecalis, and E. faecium strains were found to be resistant to our isolated phage (Table 1 ).

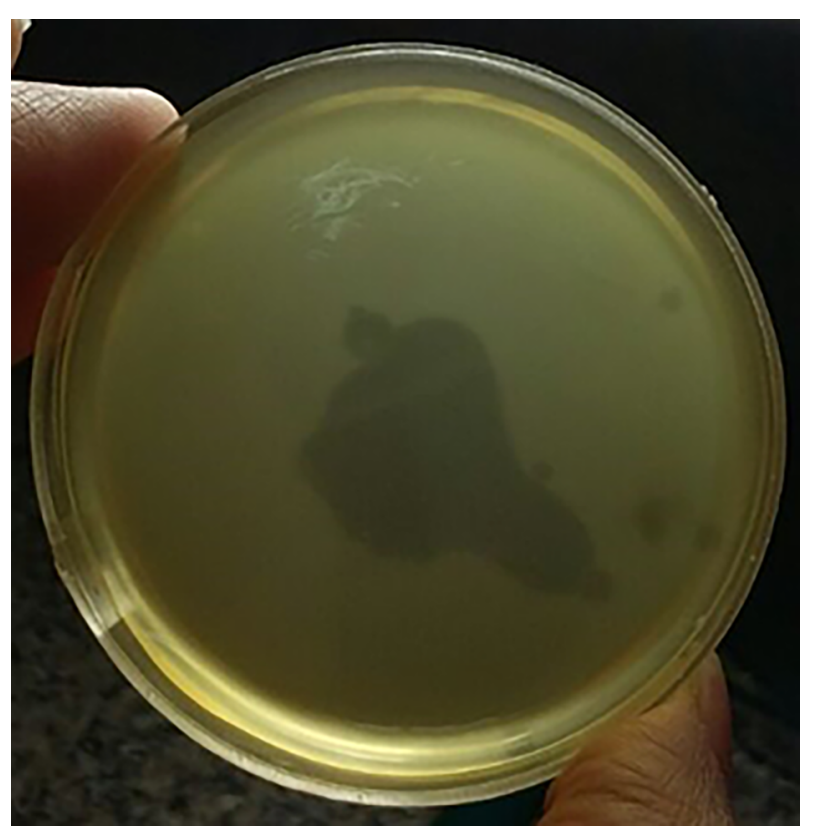

Figure 1. Spot test

\subsection{Morphology of the Lytic Bacteriophage}

The designation of morphological characteristics by electron microscopy revealed that this phage was a member of the Myoviridea family with a contractile, long, and relatively thick tail and isomeric large head with about 220 and $100 \mathrm{~nm}$ in diameter, respectively (Figure 2). 

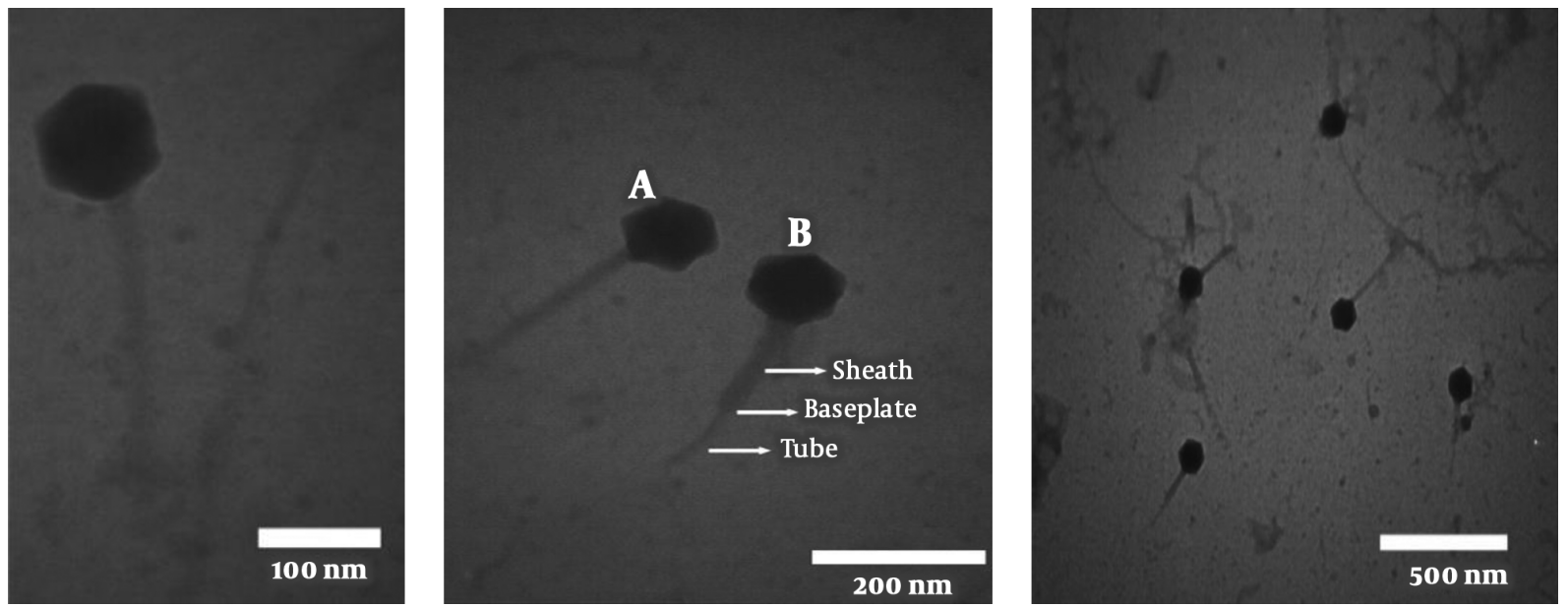

Figure 2. The TEM image of phage MH-1 belonging to the Myoviridea family. A indicates the non-contracted and B contracted tails, respectively. The phages were negatively stained with 1\% (wt/v) uranyl acetate and observed using a Zeiss LEO 906 transmission electron microscope (Carl Zeiss LEO EM $906 \mathrm{E}$, Germany) at an accelerating voltage of $100 \mathrm{kV}$.

\begin{tabular}{lccc}
\hline \multicolumn{3}{l}{ Table 1. Bacterial Strains Used for Determination of Isolated Phage Host Range } \\
\hline $\begin{array}{l}\text { Bacterial } \\
\text { Strain }\end{array}$ & $\begin{array}{c}\text { Number of } \\
\text { Isolates }\end{array}$ & $\begin{array}{c}\text { Plaque } \\
\text { Formation }\end{array}$ & Reference \\
\hline MRSA & 30 & 27 out of 30 & $\begin{array}{c}\text { Clinical isolates } \\
\text { (burn patients) }\end{array}$ \\
\hline MSSA & 30 & 26 out of 30 & $\begin{array}{l}\text { Clinical isolates } \\
\text { (burn patients) }\end{array}$ \\
\hline S. epidermidis & 30 & $\begin{array}{c}\text { Not susceptible } \\
\text { to phage MH-1 }\end{array}$ & Clinical isolates \\
\hline E.faecalis & 6 & $\begin{array}{c}\text { Not susceptible } \\
\text { to phage MH-1 }\end{array}$ & Clinical isolates \\
\hline E.faecium & 30 & $\begin{array}{c}\text { Not susceptible } \\
\text { to phage MH-1 }\end{array}$ & Clinical isolates \\
\hline
\end{tabular}

\subsection{Determination of Bacteriophage Titer}

The phage titer was ascertained by the serial dilution and DLA method. Plaques were counted after overnight incubation at $37^{\circ} \mathrm{C}$ and the titer of the isolated phage was determined to be $1 \times 10^{9} \mathrm{PFU} / \mathrm{ml}$ (Figure 3 ).

\subsection{Latent Time and Phage Burst Size}

To determine the latent time and burst size of the phage MH-1, a one-step growth curve analysis was performed. From the analysis of the MH-1 one-step growth curve, the latent period was estimated to be about $20 \mathrm{~min}$. The burst size was 190 PFU per infected cell (Figure 4).

\subsection{Isolation of Genomic DNA of Bacteriophages}

The genomic DNA of phage MH-1 was $<\sim 23 \mathrm{kbp}$ and it was totally digested by DNase I but not by RNase A (Figure 5). The EcoRI, HaeIII, XbaI, SacII, and EcoRV restriction enzymes digested the phage DNA. However, the phage

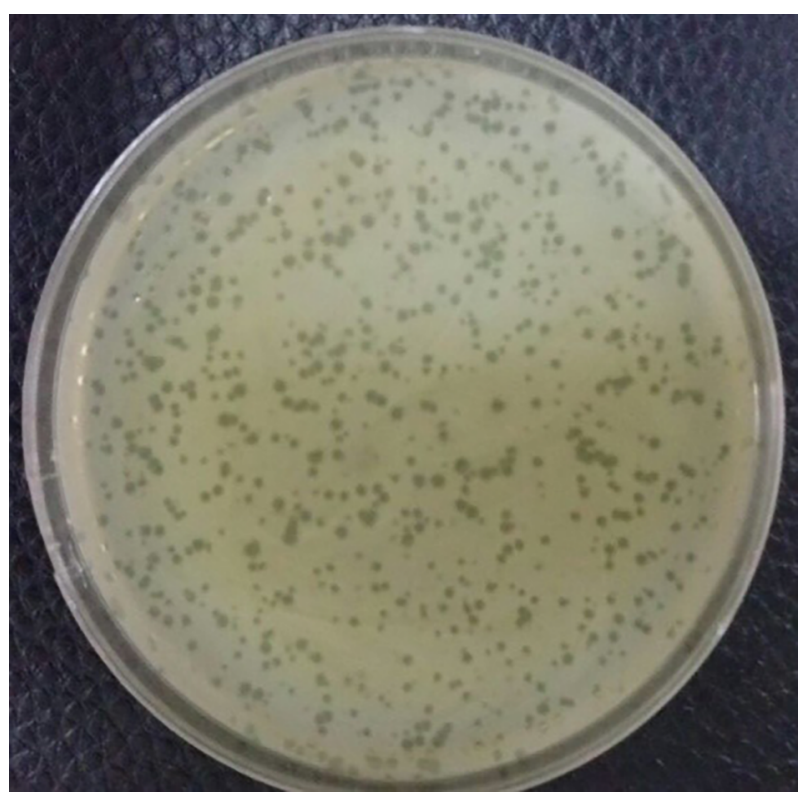

Figure 3. The titer of bacteriophage MH-1 assessed with DLA method

genome seemed to be resistant to digestion by the SmaI restriction enzyme (Figure 6).

\section{Discussion}

Treatment of staphylococcal infections is becoming increasingly difficult in view of the widespread presence of MRSA in burn wards (7). Therefore, the necessity for an al- 


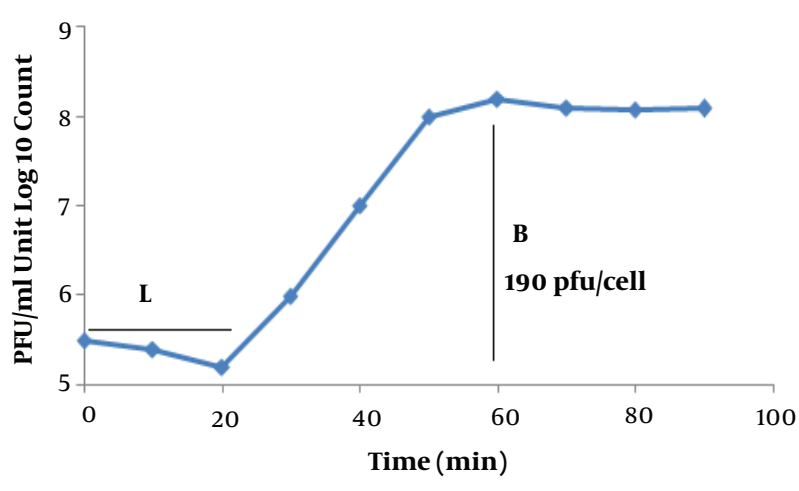

Figure 4. One-step growth curves of isolated phage. L, latent time; B, burst size.

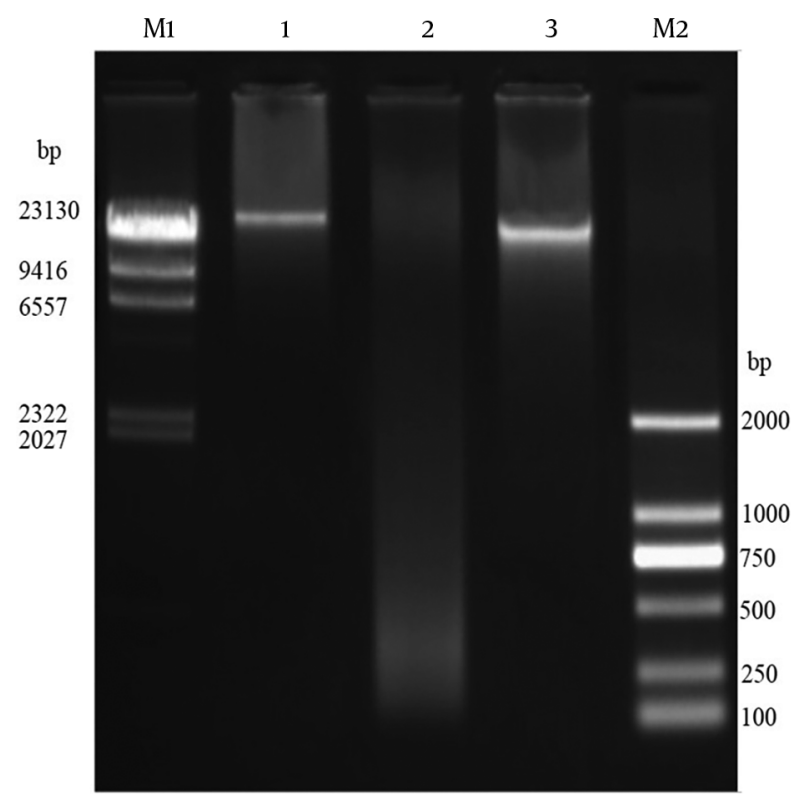

Figure 5. Agarose gel electrophoresis of MH-1 phage genomic DNA. It was treated with Rnase A and Dnase I. Lane M1, $\lambda$-Hind III digest DNA size marker; lane 1, untreated DNA; lane 2, Dnase I digested DNA; lane 3, Rnase A treated DNA; Lane M2, D2000 size marker.

ternative therapeutic method other than antibiotics seems absolutely crucial. Our study highlights the bacteriophage use as a possible alternative solution. Phage MH-1 showed broad lytic activities (90\%) and promising potential for phage therapy.

A few studies are available concerning MRSA bacteriophages in Tehran, Iran, and there is limited information about these local phages and their therapeutic potential. Therefore, in the current study, we carried out a study for the isolation of new staphylococcal bacteriophages that would be specifically active against MRSA strains isolated

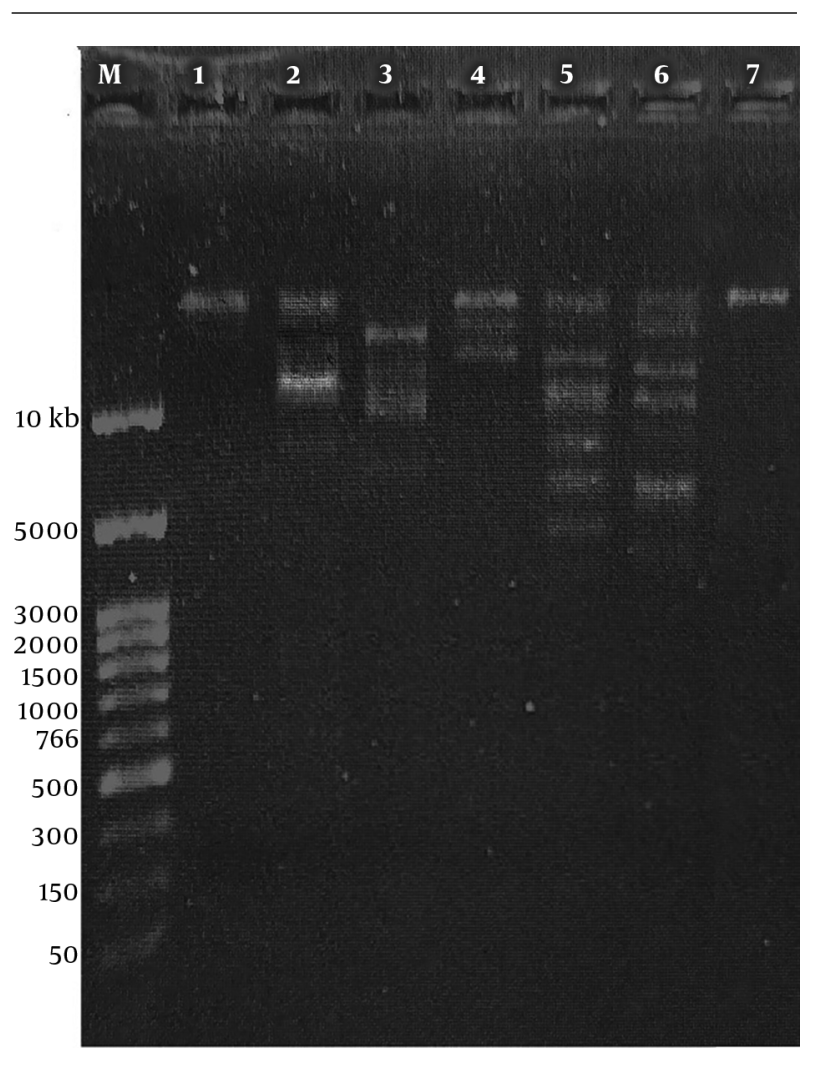

Figure 6. DNA restriction endonuclease digestion of MH-1 from the Myoviridae family. Lane M, $10 \mathrm{~Kb}$ DNA size marker; lane 1, not digested DNA; lane 2, EcoRV; lane 3, EcoR; lane 4, XbaI; lane 5: HaeIII; lane 6, SacII; lane 7, SmaI.

from burn patients. In the first step, a total of 30 MRSA isolates were collected to be used as hosts. Further characterization was carried out to confirm that the bacteria were $S$. aureus as expected and to ascertain their resistance to methicillin. Bacteriophage screening, the evaluation of their lytic abilities, and host range determination were the next steps. In the present study, we successfully isolated six virulent phages against MRSA from Motahari hospital sewage over the course of six months. In various studies, such as our study, wastewater has been used as a phage isolation reservoir (29-33). The $\mathrm{MH}-1$ titer was determined to be $1 \times 10^{9} \mathrm{PFU} / \mathrm{mL}$; therefore, hospital sewage seems to be a good source for the isolation of this phage. This suggests that potentially valuable therapeutic phages can be easily recovered from such sources and wastewater may have diverse phage populations that could be used for a wide range of applications. Many phages form transparent plaques and are typical of lytic (virulent) phages, whereas phages with the ability to lysogenize host cells (temperate phages) produce opaque plaques. Some phages produce halo plaques, meaning they have semi-transparent areas around the plaques. Halos are due to the release and sub- 
sequent activity of soluble enzymes produced by a phage that degrade the cell wall (34). After $18 \mathrm{~h}$ incubation at $37^{\circ} \mathrm{C}$, the $\mathrm{MH}-1$ phage produced clear plaques without halo with $0.5-2 \mathrm{~mm}$ in diameter, which is further indicative of the strict lytic nature of the isolated phage.

Phages can detect bacterial cell surface components including lipopolysaccharide (LPS), peptidoglycan, teichoic acids, outer membrane proteins, oligosaccharides, capsules, and type IV fimbria for the binding process. The specificity of the interaction between phage surface structures and host cell surface receptors is more influential on the bacterial host phage range (35-39). In this study, MH-1 showed broad lytic activities on the tested MRSA and MSSA strains collected from burn patients. Most of our S. aureus strains (53 of 60 strains) were lysed by the isolated phage but no plaque production was observed in the examined S. epidermidis, E. faecalis, and E. faecium strains. This result suggests that the isolated phage was completely specific for S. aureus but there was no difference in susceptibility to the isolated phage between methicillin-resistant and methicillin-sensitive strains. Thus, the MH-1 phage can be used as a disinfectant for circulating $S$. aureus strains in burn care units and prevent the spread of bacteria and antibiotic resistance.

Morphological characteristics of phages can be used for their classification. While there is a variety of different morphological phage types, most S. aureus phages possess icosahedral capsids whit double-stranded (ds) DNA as a genome and belong to the caudovirales order (tailed phages). This order is further classified based on the tail morphology into three major families: Podoviridae (characterized by short non-contractile tails), Myoviridea (equipped with long contractile tails), and Siphoviridae (with long, flexible, non-contractile tails) $(40,41)$. Electron microscopy observation of phage $\mathrm{MH}-1$ revealed that this phage belonged to the Myoviridea family. Phages from the Myoviridea family have double-layered contractile tails composed of an inner tube covered by an outer sheath and ended by a base plate (Figure 2). The outer sheath contraction of the tail pushes the tube through the bacterial cell wall and creates a channel for the viral genome delivery into the host cell's cytoplasm (42). There are reports of other studies that have isolated myophages for Staphylococcus aureus $(8,43)$.

The one-step growth curve was determined to understand the growth of the phage in S. aureus ATCC 43300 as a host. The isolated phage had a short latent period (20 min) and a large burst size (190 PFU/cell). The short latent time showed that the time needed to replicate the virus inside the host is very short and a new generation of phage will be propagated after $20 \mathrm{~min}$. This feature shows a high therapeutic potential for this phage. Moreover, the brut size of this phage could be of relevant interest because it provides high concentrations needed for phage therapy with little propagation. All of these properties make the $\mathrm{MH}-1$ phage a suitable candidate for biocontrol of this resistant bacterium.

The digestion of DNA with DNase I, but not with RNase A, evidenced that the isolated phage had the ds DNA, as expected. To confirm this result, the extracted genome of the phage was digested with six restriction enzymes. The isolated phage DNA samples were sensitive to EcoRV, EcoRI, XbaI, and HaeIII, and exhibited different restriction endonuclease patterns. Additionally, it seems that the genomic DNA of the isolated phage lacked target sequences recognized by the SmaI restriction enzyme. Phages have developed different anti-restriction strategies against restriction-modification systems (R-M) of bacteria. This system operates a defense against phage infections by means of endonuclease and methyltransferase enzymes (44). The R-M system protects methylated bacterial DNA and cuts off the foreign unmethylated DNA in the identical sequence. If oligonucleotide recognition sequences are present, an unmodified DNA molecule will be hydrolyzed by restriction endonucleases. Point mutations or acquisitions of the cognate methylase gene are the strategies used by bacteriophages to change endonuclease recognition sequences in their genomes (44). However, for the exact determination of recognition sequences in the DNA of phage $\mathrm{MH}-1$, complete genome sequencing is required.

In this study, phage MH-1 was isolated and characterized as a new biological strategy to prevent MRSA infection in burn patients. Its specificity, remarkable lytic effect, and broad-host-range for MRSA strains emphasized that it has a considerable potential to use for prophylaxis and treatment of staphylococcal infections. Because of these features, the MH-1 phage can also be used as a component of anti-staphylococcal and other antibacterial cocktails. It is obvious that additional studies are required to identify the lytic effect of this phage on MRSA isolates from different sources. Additionally, in vivo studies on experimentally induced animal or human infections should be carried out to fully ascertain the phage therapeutic potentials.

\subsection{Conclusions}

The isolation of specific lytic phages to use against multidrug-resistant Staphylococcus aureus, especially in burn patients, can be promising for the treatment of MRSA infections in the future. In addition, given the cost imposed by mortality and morbidity due to the widespread presence of multidrug-resistant $S$. aureus strains and the lack of an effective solution to this problem, the evaluation of phage therapeutics in human disease management seems to be a reasonable proposition. As a result, phage 
therapy can be an alternative to antibiotics to replace them when they fail. This treatment may help prevent potentially fatal infections in the hospital setting. Moreover, the substantially lower cost of phage therapy is another important reason for its broader consideration in the current period of the global crisis in antibiotic resistance and health care economy.

\section{Acknowledgments}

This study was financially supported by a research grant (no.: 26981-30-04-94) for a Ph.D. thesis at Iran University of Medical Sciences (Tehran, Iran) for which we are very grateful.

\section{Footnotes}

Authors' Contribution: Study concept and design: Masoume Hallajzadeh and Nour Amirmozafari. Analysis and interpretation of data: Masoume Hallajzadeh and Ali Mojtahedi. Drafting of the manuscript: Masoume Hallajzadeh. Critical revision of the manuscript for important intellectual content: Masoume Hallajzadeh, Nour Amirmozafari, and Vahid Pirhajati Mahabadi. Administrative, technical, and material support: Nour Amirmozafari and Vahid Pirhajati Mahabadi. Study supervision: Nour Amirmozafari and Ali Mojtahedi.

Conflict of Interests: The authors have declared no conflicts of interest.

Funding/Support: This study was financially supported by a research grant (no.: 26981-30-04-94) for Ph.D. thesis at Iran University of Medical Sciences (Tehran, Iran).

\section{References}

1. Sussman M. Phage therapy as a MRSA treatment. Sci J Lander Coll Arts Sci. 2016;10(1):8

2. Roach DR, Debarbieux L. Phage therapy: Awakening a sleeping giant. Emerging Top Life Sci. 2017;1(1):93-103.

3. Batabyal B, Kundu GKR, Biswas S. Methicillin-resistant Staphylococcus aureus: A brief review. Int Res J Biol Sci. 2012;1(17):65-71.

4. Synnott AJ, Kuang Y, Kurimoto M, Yamamichi K, Iwano H, Tanji Y. Isolation from sewage influent and characterization of novel Staphylococcus aureus bacteriophages with wide host ranges and potent lytic capabilities. Appl Environ Microbiol. 2009;75(13):448390. doi: 10.1128/AEM.02641-08. [PubMed: 19411410]. [PubMed Central: PMC2704828].

5. Shahsavan S, Emaneini M, Noorazar Khoshgnab B, Khoramian B, Asadollahi P, Aligholi M, et al. A high prevalence of mupirocin and macrolide resistance determinant among Staphylococcus aureus strains isolated from burnt patients. Burns. 2012;38(3):378-82. doi: 10.1016/j.burns.2011.09.004. [PubMed: 22040930].

6. Goudarzi M, Kobayashi N, Hashemi A, Fazeli M, Navidinia M. Genetic variability of methicillin resistant Staphylococcus aureus strains isolated from burns patients. Osong Public Health Res Perspect. 2019;10(3):170-6. doi: 10.24171/j.phrp.2019.10.3.08. [PubMed: 31263666]. [PubMed Central: PMC6590875].
7. Issler-Fisher AC, McKew G, Fisher OM, Harish V, Gottlieb T, Maitz PK. Risk factors for, and the effect of MRSA colonization on the clinical outcomes of severely burnt patients. Burns. 2015;41(6):1212-20. doi 10.1016/j.burns.2015.03.003. [PubMed: 26150350].

8. Abatangelo V, Peressutti Bacci N, Boncompain CA, Amadio AF, Carrasco S, Suarez CA, et al. Correction: Broad-range lytic bacteriophages that kill Staphylococcus aureus local field strains. PLoS One.2017;12(10). e0187387. doi:10.1371/journal.pone.0187387. [PubMed: 29077755]. [PubMed Central: PMC5659814].

9. Gutierrez D, Fernandez L, Rodriguez A, Garcia P. Are phage lytic proteins the secret weapon to kill Staphylococcus aureus? mBio. 2018;9(1). doi: 10.1128/mBio.01923-17. [PubMed: 29362234]. [PubMed Central: PMC5784253].

10. Strauss L, Stegger M, Akpaka PE, Alabi A, Breurec S, Coombs G, et al. Origin, evolution, and global transmission of communityacquired Staphylococcus aureus ST8. Proc Natl Acad Sci U S A. 2017;114(49):E10596-604. doi: 10.1073/pnas.1702472114. [PubMed: 29158405]. [PubMed Central: PMC5724248].

11. Hassoun A, Linden PK, Friedman B. Incidence, prevalence, and management of MRSA bacteremia across patient populations-a review of recent developments in MRSA management and treatment. Crit Care. 2017;21(1):211. doi: 10.1186/s13054-017-1801-3. [PubMed: 28807042] [PubMed Central: PMC5557425].

12. Goudarzi M, Navidinia M, Beiranvand E, Goudarzi H. Phenotypic and molecular characterization of methicillin-resistant Staphylococcus aureus clones carrying the panton-valentine leukocidin genes disseminating in Iranian hospitals. Microb Drug Resist. 2018;24(10):154351. doi: 10.1089/mdr.2018.0033. [PubMed: 29894277].

13. Navidinia M, Goudarzi M. Overview perspective of bacterial strategies of resistance to biocides and antibiotics. Arch Clin Infect Dis. 2019;14(2). e65744. doi: 10.5812/archcid.65744.

14. Takemura-Uchiyama I, Uchiyama J, Kato S, Inoue T, Ujihara T, Ohara $\mathrm{N}$, et al. Evaluating efficacy of bacteriophage therapy against Staphylococcus aureus infections using a silkworm larval infection model FEMS Microbiol Lett. 2013;347(1):52-60. doi: 10.1111/1574-6968.12220. [PubMed: 23869440].

15. Estrella LA, Quinones J, Henry M, Hannah RM, Pope RK, Hamilton $\mathrm{T}$, et al. Characterization of novel Staphylococcus aureus lytic phage and defining their combinatorial virulence using the OmniLog(R) system. Bacteriophage. 2016;6(3). e1219440. doi: 10.1080/21597081.2016.1219440. [PubMed: 27738555]. [PubMed Central: PMC5056778].

16. Pincus NB, Reckhow JD, Saleem D, Jammeh ML, Datta SK, Myles IA Strain specific phage treatment for Staphylococcus aureus infection is influenced by host immunity and site of infection. PLoS One. 2015;10(4). e0124280. doi: 10.1371/journal.pone.0124280. [PubMed: 25909449]. [PubMed Central: PMC4409319].

17. Babakir-Mina M, Othman N, Najmuldeen $\mathrm{HH}$, Noori CK, Fatah CF, Perno CF, et al. Antibiotic susceptibility of vancomyin and nitrofurantoin in Staphylococcus aureus isolated from burnt patients in Sulaimaniyah, Iraqi Kurdistan. New Microbiol. 2012;35(4):439-46. [PubMed: 23109011].

18. Weber-Dabrowska B, Górski A. Phage therapy of staphylococcal infections (including MRSA) may be less expensive than antibiotic treatment. Postepy Hig Med Dosw. 2007;61:461-5.

19. Wang Z, Kong L, Liu Y, Fu Q, Cui Z, Wang J, et al. A phage lysin fused to a cell-penetrating peptide kills intracellular methicillin-resistant Staphylococcus aureus in keratinocytes and has potential as a treatment for skin infections in mice. Appl Environ Microbiol. 2018;84(12) doi: 10.1128/AEM.00380-18. [PubMed: 29625989]. [PubMed Central: PMC5981068]. 
20. Iwano H, Inoue Y, Takasago T, Kobayashi H, Furusawa T, Taniguchi $\mathrm{K}$, et al. Bacteriophage PhiSA012 Has a broad host range against Staphylococcus aureus and effective lytic capacity in a mouse mastitis model. Biology (Basel). 2018;7(1). doi: 10.3390/biology7010008. [PubMed: 29315249]. [PubMed Central: PMC5872034].

21. Mohammed-Ali MN, Jamalludeen NM. Isolation and characterization of bacteriophage against methicillin resistant Staphylococcus aureus. J Med Microb Diagn. 2015;5(213):2161-703.1000213.

22. Verstappen KM, Tulinski P, Duim B, Fluit AC, Carney J, van Nes A, et al. The effectiveness of bacteriophages against methicillin-resistant Staphylococcus aureus ST398 nasal colonization in pigs. PLoS One. 2016;11(8). e0160242. doi: 10.1371/journal.pone.0160242. [PubMed: 27487020]. [PubMed Central: PMC4972443].

23. Jensen KC, Hair BB, Wienclaw TM, Murdock MH, Hatch JB, Trent AT, et al. Isolation and host range of bacteriophage with lytic activity against methicillin-resistant Staphylococcus aureus and potential use as a fomite decontaminant. PLoS One. 2015;10(7). e0131714. doi: 10.1371/journal.pone.0131714. [PubMed: 26131892]. [PubMed Central: PMC4488860].

24. Kutter E. Phage host range and efficiency of plating. Methods Mol Biol. 2009;501:141-9. doi: 10.1007/978-1-60327-164-6_14. [PubMed: 19066818].

25. Bonilla N, Rojas MI, Netto Flores Cruz G, Hung SH, Rohwer F, Barr JJ. Phage on tap-a quick and efficient protocol for the preparation of bacteriophage laboratory stocks. PeerJ. 2016;4. e2261. doi: 10.7717/peerj.2261. [PubMed: 27547567]. [PubMed Central: PMC4975003].

26. Clokie MRJ, Kropinski A. Methods and protocols, volume 1: Isolation, characterization, and interactions. Germany: Springer; 2009.

27. Adriaenssens EM, Wittmann J, Kuhn JH, Turner D, Sullivan MB, Dutilh BE, et al. Taxonomy of prokaryotic viruses: 2017 update from the ICTV bacterial and archaeal viruses subcommittee. Arch Virol. 2018;163(4):1125-9. doi: 10.1007/s00705-018-3723-z. [PubMed: 29356990].

28. Wang Z, Zheng P, Ji W, Fu Q, Wang H, Yan Y, et al. SLPW: A virulent bacteriophage targeting methicillin-resistant Staphylococcus aureus in vitro and in vivo. Front Microbiol. 2016;7:934. doi: 10.3389/fmicb.2016.00934. [PubMed: 27379064]. [PubMed Central: PMC4908117].

29. Sundar MM, Nagananda GS, Das A, Bhattacharya S, Suryan S. Isolation of host-specific bacteriophages from sewage against human pathogens. Asian J Biotechnol. 2009;1(4):163-70. doi: 10.3923/ajbkr.2009.163.170.

30. Mattila S, Ruotsalainen P, Jalasvuori M. On-demand isolation of bacteriophages against drug-resistant bacteria for personalized phage therapy. Front Microbiol. 2015;6:1271. doi: 10.3389/fmicb.2015.01271. [PubMed: 26617601]. [PubMed Central: PMC4643220].

31. Bibi Z, Abbas Z, Rehman S. The phage P.E1 isolated from hospital sewage reduces the growth of Escherichia coli. Biocontrol Sci Technol. 2015;26(2):181-8. doi: 10.1080/09583157.2015.1086311.

32. Gautam B, Aryal L, Adhikari S, Rana M, Rajbhanshi A, Ghale S, et al. Iso- lation of bacteriophage from guheswori sewage treatment plant capable of infecting pathogens. Res Pharm Health Sci. 2018;4(2):465-70. doi: 10.32463/rphs.2018.v04i02.11.

33. Daneshgar F, Soltan Dallal MM, Hosseini F. Isolation of Yersinia enterocolitica bacteriophage from hospital wastewater. Int J Enteric Pathog. 2017;6(1):18-21. doi: 10.15171/ijep.2018.05.

34. Jurczak-Kurek A, Gasior T, Nejman-Falenczyk B, Bloch S, Dydecka A, Topka G, et al. Biodiversity of bacteriophages: Morphological and biological properties of a large group of phages isolated from urban sewage. Sci Rep. 2016;6:34338. doi: 10.1038/srep34338. [PubMed: 27698408]. [PubMed Central: PMC5048108].

35. Abedon ST. Bacteriophage ecology: Population growth, evolution, and impact of bacterial viruses. Cambridge: Cambridge University Press; 2008. doi: 10.1017/cbo9780511541483.

36. Drulis-Kawa Z, Majkowska-Skrobek G, Maciejewska B, Delattre AS, Lavigne R. Learning from bacteriophages - advantages and limitations of phage and phage-encoded protein applications. Curr Protein PeptSci.2012;13(8):699-722. doi:10.2174/138920312804871193. [PubMed: 23305359]. [PubMed Central: PMC3594737].

37. Kutter E, Sulakvelidze A. Bacteriophages: Biology and applications. United States: CRC Pres; 2004. doi: 10.1201/9780203491751.

38. Sulakvelidze A, Alavidze Z, Morris JG, Jr. Bacteriophage therapy. Antimicrob Agents Chemother. 2001;45(3):649-59. doi: 10.1128/AAC.45.3.649-659.2001. [PubMed: 11181338]. [PubMed Central: PMC90351]

39. Weinbauer MG. Ecology of prokaryotic viruses. FEMS Microbiol Rev. 2004;28(2):127-81. doi: 10.1016/j.femsre.2003.08.001. [PubMed: 15109783].

40. Xia G, Wolz C. Phages of Staphylococcus aureus and their impact on host evolution. Infect Genet Evol. 2014;21:593-601. doi: 10.1016/j.meegid.2013.04.022. [PubMed: 23660485].

41. Fu X, Walter MH, Paredes A, Morais MC, Liu J. The mechanism of DNA ejection in the Bacillus anthracis spore-binding phage 8a revealed by cryo-electron tomography. Virology. 2011;421(2):141-8. doi: 10.1016/j.virol.2011.08.028. [PubMed: 22018785]. [PubMed Central: PMC3939024].

42. Aksyuk AA, Kurochkina LP, Fokine A, Forouhar F, Mesyanzhinov VV, Tong L, et al. Structural conservation of the myoviridae phage tail sheath protein fold. Structure. 2011;19(12):1885-94. doi: 10.1016/j.str.2011.09.012. [PubMed: 22153511]. [PubMed Central: PMC3256926].

43. El Haddad L, Ben Abdallah N, Plante PL, Dumaresq J, Katsarava R, Labrie S, et al. Improving the safety of Staphylococcus aureus polyvalent phages by their production on a Staphylococcus xylosus strain. PLoS One. 2014;9(7). e102600. doi: 10.1371/journal.pone.0102600. [PubMed: 25061757]. [PubMed Central: PMC4111496].

44. Marek A, Pyzik E, Stepien-Pysniak D, Urban-Chmiel R, Nowaczek A. Characterization of bacteriophages and their carriage in Staphylococcus aureus isolated from broilers in Poland. Br Poult Sci. 2019;60(4):373-80. doi: 10.1080/00071668.2018.1426831. [PubMed: 29320875]. 